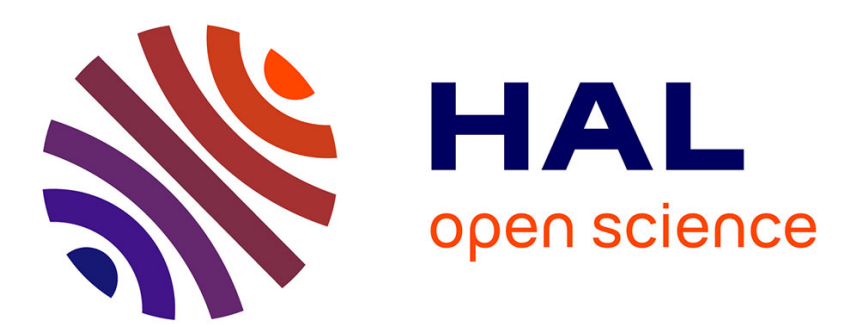

\title{
Novel magnetoelectric composites of cobalt iron alloy and barium titanate
}

\author{
Till Walther, Roberto Köferstein, Stefan G Ebbinghaus
}

\section{To cite this version:}

Till Walther, Roberto Köferstein, Stefan G Ebbinghaus. Novel magnetoelectric composites of cobalt iron alloy and barium titanate. Journal of the American Ceramic Society, 2017, 100 (4), pp.1502-1507. 10.1111/jace.14744 . hal-01991452

\section{HAL Id: hal-01991452 \\ https://hal.science/hal-01991452}

Submitted on 25 Jan 2019

HAL is a multi-disciplinary open access archive for the deposit and dissemination of scientific research documents, whether they are published or not. The documents may come from teaching and research institutions in France or abroad, or from public or private research centers.
L'archive ouverte pluridisciplinaire HAL, est destinée au dépôt et à la diffusion de documents scientifiques de niveau recherche, publiés ou non, émanant des établissements d'enseignement et de recherche français ou étrangers, des laboratoires publics ou privés. 


\title{
Journal of the American Ceramic Society 100 (2017) 1502-1507
}

\author{
DOI: $10.1111 /$ jace.14744
}

\section{http://dx.doi.org/10.1111/jace.14744}

\section{Novel magnetoelectric composites of cobalt iron alloy and barium titanate}

\author{
Till Walther, Roberto Köferstein, Stefan G. Ebbinghaus \\ Institute of Chemistry, Martin Luther University Halle-Wittenberg, \\ Kurt-Mothes-Strasse 2, 06120 Halle, Germany.
}

\begin{abstract}
Magnetoelectric barium titanate ceramics with embedded cobalt iron alloy particles $\left(\mathrm{Co}_{1 / 3} \mathrm{Fe}_{2 / 3}\right)_{\mathrm{x}}-\left(\mathrm{BaTiO}_{3}\right)(1-\mathrm{x})$, with $\mathrm{x}=0.2,0.4$, and 0.6 , were prepared by a polyol-mediated synthesis with subsequent sintering in a reducing forming gas atmosphere. The samples were characterized by XRD and SEM/EDX measurements. The sizes of the $\mathrm{Co}_{1 / 3} \mathrm{Fe}_{2 / 3}$ grains increase with $\mathrm{x}$. Impedance spectroscopy showed a behavior similar to pure $\mathrm{BaTiO}$, in particular the occurrence of the ferroelectric-paraelectric phase transition, and high permittivities for the sample with $x=0.6$, that is, near the percolation threshold. The samples exhibit soft ferromagnetic properties with large saturation magnetizations of $2.5 \mu_{\mathrm{B}} /$ atom and narrow hystereses. Detailed magnetoelectric investigations revealed a unique DC-field dependence of $\alpha \mathrm{ME}$ for all three compositions. Most remarkably, the sample with $\mathrm{x}=0.4$ possesses a broad ME hysteresis and an inversion of the sign of $\alpha_{\mathrm{ME}}$ at $5 \mathrm{kOe}$.
\end{abstract}

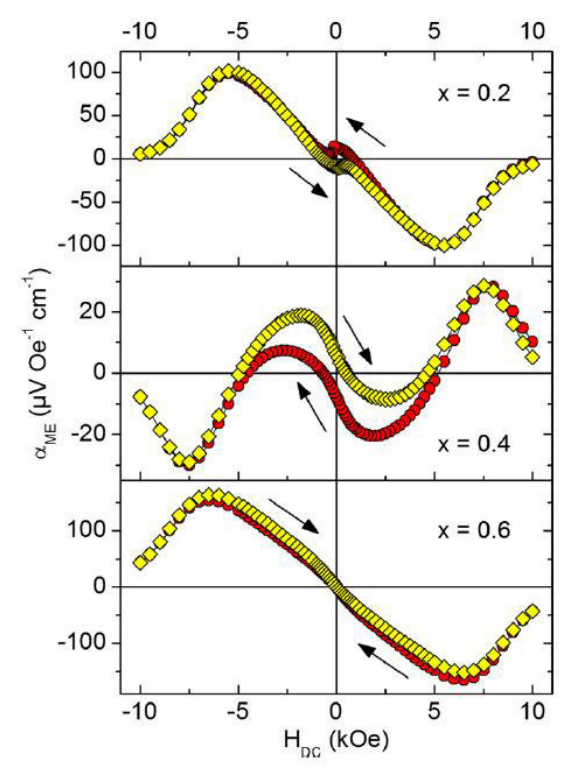




\section{Novel magnetoelectric composites of cobalt iron alloy and barium titanate}

\section{Till Walther (D) | Roberto Köferstein | Stefan G. Ebbinghaus}

Institute of Chemistry, Martin Luther University Halle-Wittenberg, Halle/Saale,

2 Germany

\section{Correspondence}

Till Walther, Institute of Chemistry, Martin Luther University Halle-

Wittenberg, Halle/Saale, Germany.

Email: stefan.ebbinghaus@chemie. uni-halle.de

\section{Funding information}

Deutsche Forschungsgemeinschaft, Grant/ Award Number: SFB 762;

\section{1 | INTRODUCTION}

Materials that exhibit at least two ferroic order phenomena are called multiferroics. ${ }^{1}$ Of these, magnetoelectrics with a coupling between magnetostrictive and piezoelectric properties are of special interest because they allow the manipulation of magnetization with electric fields and/or of the polarization by magnetic fields. ${ }^{2}$ Since this field of science was initiated, the hunt for high or unusual magnetoelectric coupling effects is on. To date, many compositions and connectivities of compounds have been investigated both theoretically and experimentally. So far one of the most promising combinations are layered composites of metals/ alloys with perovskites. ${ }^{3,4}$ They exhibit magnetoelectric coefficients $\left(\alpha_{\mathrm{ME}}\right)$ ranging from a few $\mathrm{mV} \mathrm{Oe}^{-1} \mathrm{~cm}^{-1}$ at low $\mathrm{H}_{\mathrm{AC}}$ frequencies up to several $\mathrm{V} \mathrm{Oe}^{-1} \mathrm{~cm}^{-1}$ at resonance conditions (several $\mathrm{kHz}$, depending on the system). ${ }^{5-}$ ${ }^{9}$ In addition, magnetoelectric effects of ferroelectric thin films with embedded metal particles have been investigated. ${ }^{10,11}$ In contrast, no magnetoelectric investigations on 0-3 metal-perovskite ceramics have been reported yet, although various synthesis routes for metal-ceramic composites are described in the literature. ${ }^{12-18}$

In this study, the first detailed magnetoelectric investigations on 0-3 composites of $\mathrm{Co}_{1 / 3} \mathrm{Fe}_{2 / 3}$ in combination with $\mathrm{BaTiO}_{3}$ are reported. Samples with varying $\mathrm{Co}_{1 / 3} \mathrm{Fe}_{2 / 3}$ content $(x=0.2,0.4$ and 0.6$)$ were prepared by a polyolmediated synthesis with subsequent calcination and sintering under reducing conditions. $\mathrm{BaTiO}_{3}$ is widely investigated for magnetoelectric composites and is used as piezostrictive matrix component. The alloy of cobalt and iron with a molar ratio of $\mathrm{Co}: \mathrm{Fe} 1: 2$ was chosen as metallic component because it shows high magnetostriction and the highest saturation magnetization of $3 \mathrm{~d}$ metal alloys. ${ }^{19-21}$

\section{2 | EXPERIMENTAL SECTION}

\section{1 | Material preparation}

Three composite samples $\left(\mathrm{Co}_{1 / 3} \mathrm{Fe}_{2 / 3}\right)_{x}-\left(\mathrm{BaTiO}_{3}\right)_{(1-x)}$ with $x=0.2,0.4$, and 0.6 were synthesized in a procedure similar to the one reported in. ${ }^{22}$ 
$21 \bigcup_{\substack{\text { of } \\ \text { hemerican }}}$

In a first step, $\mathrm{Co}$ (II) and $\mathrm{Fe}$ (III) nitrates (molar ratio $1: 2)$ were dissolved in water and diethylene glycol (DEG) with $\left[\mathrm{Co}^{2+}\right]=40 \mathrm{mmol} \mathrm{L}^{-1}$. The solution was heated under reflux for 1 hour. After cooling to room temperature, acetone was added and the precipitate was centrifuged, washed with acetone and dried, resulting in a brown powder. Appropriate amounts of this precursor were suspended in stoichiometric solutions of titanium isopropoxide and barium hydroxide in DEG with $\left[\mathrm{Ba}^{2+}\right]=\left[\mathrm{Ti}^{4+}\right]=40 \mathrm{mmol} \mathrm{L}^{-1}$. After heating under reflux for 1 hour, the reaction mixture was cooled to room temperature. Addition of acetone produced a gray precipitate that was centrifuged, washed with acetone, and dried. This powder was calcined at $700^{\circ} \mathrm{C}$ in static air (1 hour), followed by a reduction in flowing forming gas $\left(80 \mathrm{~mL} \mathrm{~min}^{-1}, 10 \% \mathrm{H}_{2}, 1\right.$ hour $)$ at $950^{\circ} \mathrm{C}$. The resulting gray powder was pressed into disks $(100 \mathrm{mg}$, $\varnothing=6 \mathrm{~mm})$. Sintering under reducing conditions in forming gas at $1300^{\circ} \mathrm{C}$ for 1 hour led to black ceramic bodies with relative densities (with respect to the weighted single crystal values ${ }^{23}$ ) of $\rho \approx 85 \%$.

\subsection{Characterization}

Room-temperature X-ray diffraction patterns of crushed samples were recorded on a diffractometer (D8 Advance, Bruker Corporation, Billerica, MA, USA) operating with $\mathrm{Cu} K \alpha$ radiation. Scanning electron microscope images in backscattered electron (BSE) mode and EDX spectra were recorded with $15 \mathrm{kV}$ acceleration voltage (Phenom ProX, Phenom-World B.V., Eindhoven, the Netherlands). Grain sizes were derived from SEM images of several areas of each ceramic. The values given below are the lower and upper limits and the average grain sizes. For impedance measurements, GaIn alloy was coated on top and bottom surfaces of the ceramic bodies as electrodes. The temperature- and frequency-dependent impedance spectra $\left(0^{\circ} \mathrm{C}\right.$ $180^{\circ} \mathrm{C} ; 10^{2}-10^{7} \mathrm{~Hz}$ ) were recorded with an impedance analyzer (4192A, Hewlett-Packard, Palo Alto, CA, USA). Magnetic measurements were carried out using the ACMS option (PPMS 9, Quantum Design Inc., San Diego, CA, USA). Hysteresis loops were measured at $300 \mathrm{~K}$ with a cycling of the magnetic DC field between +90 and -90 kOe. For magnetoelectric investigations, $100 \mathrm{~nm}$ Gold electrodes were sputtered onto the sample surfaces (Sputter Coater 108auto, Cressington Scientific Instruments Ltd., Watford, UK). Electric poling was done applying a DC field of $6.5 \mathrm{kV} \mathrm{cm}{ }^{-1}$ at room temperature. The samples were heated to $200^{\circ} \mathrm{C}$ (ie, above $\mathrm{T}_{\mathrm{C}}$ of $\mathrm{BaTiO}_{3}$ ) for 1 hour (heating rate $10 \mathrm{~K} \mathrm{~min}^{-1}$ ). During heating and cooling the electric field was maintained but adjusted dynamically to a current limit of $0.1 \mathrm{~mA}$. After poling, the samples were short circuited for 10 minutes. The ME measurements were performed at $300 \mathrm{~K}$ using a custom-made setup based on the AC-Transport measurement option (PPMS 9, Quantum Design Inc., San Diego, CA, USA). A magnetic AC field of $\mathrm{H}_{\mathrm{AC}}=10$ Oe with different frequencies was applied by a solenoid with 1160 loops of copper wire. The ME voltage was measured in dependence of the magnetic DC field upon cycling between +10 and -10 kOe. Magnetic AC and DC fields were aligned parallel to the electric polarization direction as shown in Figure S1. Raw data were corrected for eddy currents measured on an empty sample holder. Since voltages caused by induction show a $90^{\circ}$ phase shift with respect to $\mathrm{H}_{\mathrm{AC}}$, only the real part of the measured voltage was considered. The magnetoelectric coefficient was calculated as $\alpha_{\mathrm{ME}}=\mathrm{U}_{\mathrm{ME}} /\left(\mathrm{H}_{\mathrm{AC}} \cdot \mathrm{h}\right)$ with $\mathrm{h}$ being the sample height.

\section{3 | RESULTS AND DISCUSSION}

\subsection{Composition and morphology}

$\mathrm{X}$-ray diffraction was used to investigate the reaction products at different stages of the synthesis as shown exemplarily for $0.6 \mathrm{Co}_{1 / 3} \mathrm{Fe}_{2 / 3}-0.4 \mathrm{BaTiO}_{3}$ in Figure S2. Directly after precipitation $\mathrm{BaCO}_{3}$ is the sole crystalline component. Calcination in air at $700^{\circ} \mathrm{C}$ leads to the formation of $\mathrm{CoFe}_{2} \mathrm{O}_{4}$ and $\mathrm{BaTiO}_{3}$ but a significant amount of $\mathrm{BaCO}_{3}$ remains in the powder.

An additional reducing step in forming gas was introduced because the direct sintering of the air-calcined powder leads to porous ceramic bodies owing to the release of $\mathrm{CO}_{2}$ from the residual $\mathrm{BaCO}_{3}$. The temperature of $950^{\circ} \mathrm{C}$ was chosen to completely decompose $\mathrm{BaCO}_{3}$ while preserving a high sintering activity of the powder. The corresponding diffractogram (Figure S2 c) reveals that only $\mathrm{Co}_{1 /}$ ${ }_{3} \mathrm{Fe}_{2 / 3}$ and $\mathrm{BaTiO}_{3}$ are present in the reduced powder.

The reducing forming gas atmosphere was also used during sintering. At $1300^{\circ} \mathrm{C}$ the samples reach a relative density of $85 \%$ after 1 hour. As depicted in Figure 1, phase pure $\left(\mathrm{Co}_{1 / 3} \mathrm{Fe}_{2 / 3}\right)_{x}-\left(\mathrm{BaTiO}_{3}\right)_{(1-x)}$ composites were obtained for all three compositions and the tetragonal modification of $\mathrm{BaTiO}_{3}$ is formed.

For morphological investigations, SEM images of the final samples were taken and EDX spectra were recorded. The results are depicted in Figure 2.

In all samples the sizes of the $\mathrm{BaTiO}_{3}$ grains range from $0.5 \mu \mathrm{m}$ to $5 \mu \mathrm{m}$, with the majority of grains being about $2 \mu \mathrm{m}$ in diameter. There are two types of $\mathrm{Co}_{1 / 3} \mathrm{Fe}_{2 / 3}$-particle distributions in the composites. In all samples isolated grains with a size of 1-2 $\mu \mathrm{m}$ are present. These are completely surrounded by the $\mathrm{BaTiO}_{3}$ matrix. The second sort of $\mathrm{Co}_{1 / 3} \mathrm{Fe}_{2 / 3}$ particles form larger interconnected areas. With increasing $x$, the fraction of the latter becomes larger: while for $x=0.2$ most of the $\mathrm{Co}_{1 / 3} \mathrm{Fe}_{2 / 3}$ consists of isolated grains, for $x=0.6$ almost the entire alloy grains are merged 


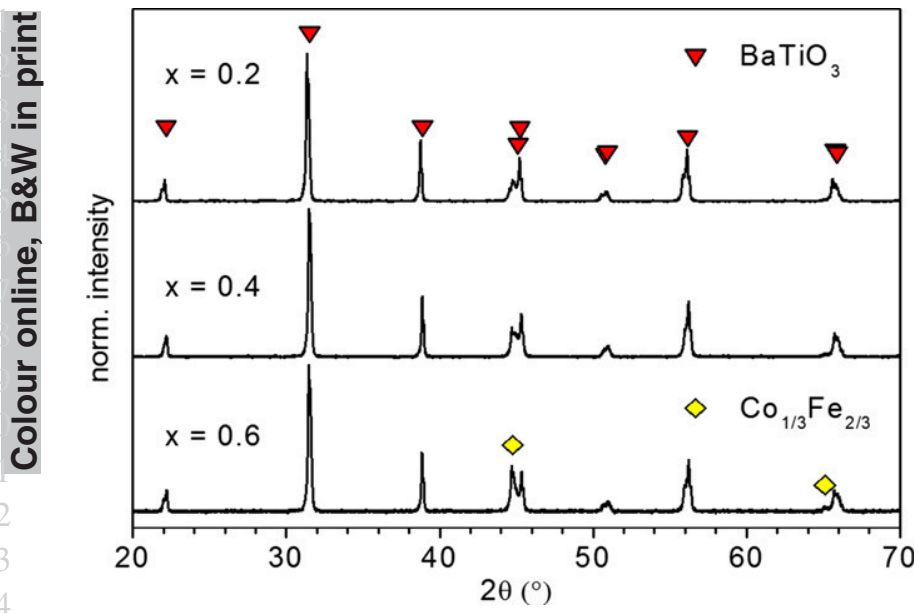

FIGURE 1 XRD patterns of $\left(\mathrm{Co}_{1 / 3} \mathrm{Fe}_{2 / 3}\right)_{x}-\left(\mathrm{BaTiO}_{3}\right)_{(1-x)}$ composites sintered at $1300^{\circ} \mathrm{C}$ with increasing $\mathrm{Co}_{1 / 3} \mathrm{Fe}_{2 / 3}$ content [Color figure can be viewed at wileyonlinelibrary.com]

and form structures of up to $4 \mu \mathrm{m}$ in width and $>10 \mu \mathrm{m}$ in length.

EDX measurements clearly show the formation of the two distinct phases. No traces of Co or Fe were found in the $\mathrm{BaTiO}_{3}$ matrix. On the other hand, small $\mathrm{Ba}$ and $\mathrm{Ti}$ signals appear in the $\mathrm{Co}_{1 / 3} \mathrm{Fe}_{2 / 3}$ spectra because of the large interaction volume of the electron beam compared to the size of the $\mathrm{Co}_{1 / 3} \mathrm{Fe}_{2 / 3}$ grains.

\section{2 | Dielectric measurements}

The dielectric properties of $\mathrm{BaTiO}_{3}$ ceramics depend on their densities and (more important) on the grain sizes. As mentioned above, these parameters are very similar for all three compositions allowing a meaningful comparison. The general behavior of the real parts of the permittivity $\left(\varepsilon_{\mathrm{r}}\right)$ resembles the one of pure $\mathrm{BaTiO}_{3}$ in the entire frequency range $\left(10^{2}\right.$ to $\left.10^{7} \mathrm{~Hz}\right)$. In Figure $\mathrm{S} 3$ of the supplementary, the temperature dependence of $\varepsilon_{\mathrm{r}}$ and the dissipation factor of the composites are shown exemplarily for $\mathrm{f}=1 \mathrm{kHz}$. The $\varepsilon_{\mathrm{r}}$ graphs exhibit maxima at the transition from the ferroto the paraelectric phase of $\mathrm{BaTiO}_{3}$ around $\mathrm{T}_{\mathrm{C}} \approx 125^{\circ} \mathrm{C}$. At $20^{\circ} \mathrm{C}$, the $\varepsilon_{\mathrm{r}}$ values for $x=0.2$ and 0.4 are very similar and almost constant over a wide frequency range (see Figure S4). In contrast for $0.6 \mathrm{Co}_{1 / 3} \mathrm{Fe}_{2 / 3}-0.4 \mathrm{BaTiO}_{3}$ the permittivity at low frequencies is up to five times higher than

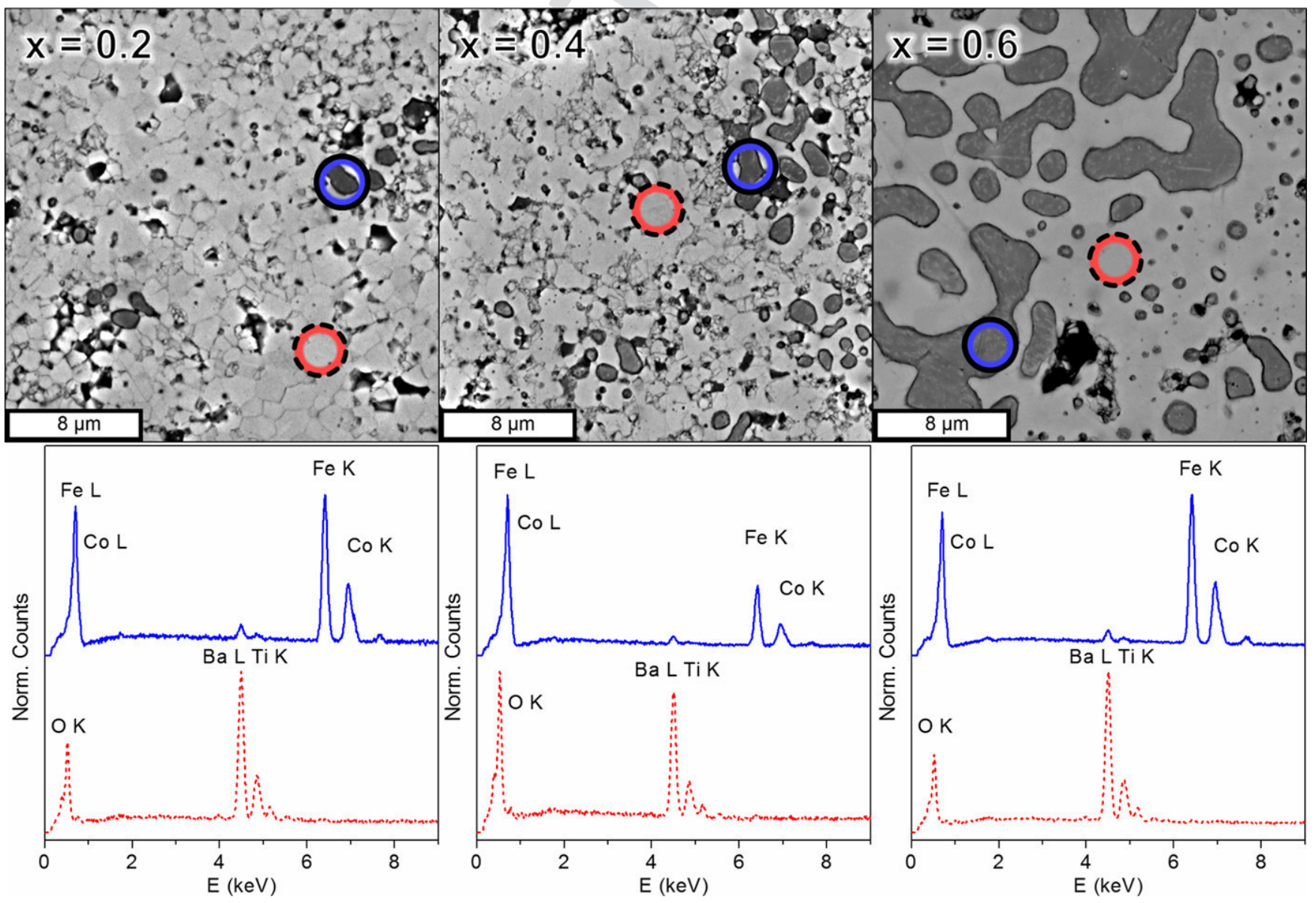

F I G URE 2 SEM images in BSE mode with position markers of the corresponding EDX spectra of $\left(\mathrm{Co}_{1 / 3} \mathrm{Fe}_{2 / 3}\right)_{x}-\left(\mathrm{BaTiO}_{3}\right)_{(1-x)}$ composites with increasing $x$ [Color figure can be viewed at wileyonlinelibrary.com] 
$41 \bigcup_{\substack{\text { of } \\ \text { hemerican }}}$

for the other two samples. In addition, $\varepsilon_{\mathrm{r}}$ shows a pronounced frequency dependence and strongly decreases above $10^{6} \mathrm{~Hz}$. The enhancement of the dielectric constant at low frequencies is known for metal- $\mathrm{BaTiO}_{3}$ ceramics with compositions close to the percolation threshold. ${ }^{14,18} \mathrm{~A}$ theoretical description is given in. ${ }^{24}$

Up to $T_{C}$ the dissipation factors increase only slightly with temperature, whereas above $130^{\circ} \mathrm{C}$ the samples get more conductive and $\tan \delta$ increases. At room temperature, the $\tan \delta$ are quite stable up to $\mathrm{f}=100 \mathrm{kHz}$ but increase considerably with higher frequencies. Over the measured temperature and frequency ranges, the dissipation factors for $x=0.2$ and 0.4 are roughly of the same magnitude, whereas $\tan \delta$ is remarkably higher for $x=0.6$.

In contrast to composites of $\mathrm{BaTiO}_{3}$ with ferrite spinels, the influence of the $\mathrm{Co}_{1 / 3} \mathrm{Fe}_{2 / 3}$ alloy on the dielectric properties is comparatively low. ${ }^{22}$ Usually, ferrite- $\mathrm{BaTiO}_{3}$ composites show Maxwell-Wagner like frequency and temperature dependencies of $\varepsilon_{\mathrm{r}}$ that are distinctively different from pure $\mathrm{BaTiO}_{3} .{ }^{25-27}$ The $\mathrm{Co}_{1 / 3} \mathrm{Fe}_{2 / 3}-\mathrm{BaTiO}_{3}$ composites, on the other hand, show only little deviations compared to pure $\mathrm{BaTiO}_{3}$. A similar behavior has already been reported for $\mathrm{Ni}-\mathrm{BaTiO}_{3}$ composites. ${ }^{14}$

\section{3 | Magnetic properties}

As shown in Figure 3, all three samples show soft ferromagnetic behavior. The saturation magnetization $\left(\mathrm{M}_{\mathrm{S}}\right)$ of the composites increases linearly with the $\mathrm{Co}_{1 / 3} \mathrm{Fe}_{2 / 3}$ content. When normalized to $x, \mathrm{M}_{\mathrm{S}}$ values of $2.5 \mu_{\mathrm{B}} /$ atom are found for all three compositions, which is the maximum saturation magnetization a $\mathrm{Co} / \mathrm{Fe}$ alloy can reach. ${ }^{20,28,29}$ The coercivities $\left(\mathrm{H}_{\mathrm{C}}\right)$ decrease with increasing $\mathrm{Co}_{1 / 3} \mathrm{Fe}_{2 / 3}$ content $(50,12,3$ Oe for $x=0.2,0.4$, and 0.6$)$, most likely

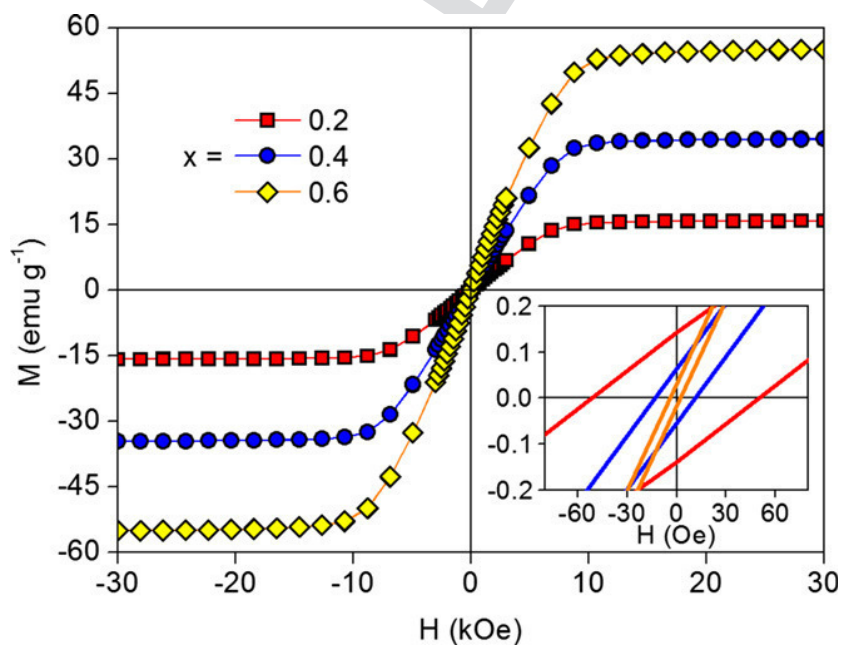

F IGURE 3 Magnetic field-dependent magnetization hystereses of $\left(\mathrm{Co}_{1 / 3} \mathrm{Fe}_{2 / 3}\right)_{x}-\left(\mathrm{BaTiO}_{3}\right)_{(1-x)}$ composites [Color figure can be viewed at wileyonlinelibrary.com] because of the larger $\mathrm{Co}_{1 / 3} \mathrm{Fe}_{2 / 3}$ grain sizes (see SEM part). ${ }^{30,31}$ Overall, the composites exhibit the expected magnetic behavior.

\section{4 | Magnetoelectric properties}

In this work, the magnetic DC field dependence of the magnetoelectric coefficient $\alpha_{\mathrm{ME}}$ is investigated for the first time for $\mathrm{CoFe}-\mathrm{BaTiO}_{3}$ 0-3 composites. The ME measurements of the three compositions were done at $300 \mathrm{~K}$. The corresponding graph for $x=0.2$ is shown in Figure 4. Upon increasing $\mathrm{H}_{\mathrm{DC}} \alpha_{\mathrm{ME}}$ reaches a maximum of $-100 \mu \mathrm{V} \mathrm{Oe}^{-1} \mathrm{~cm}^{-1}$ at $5.5 \mathrm{kOe}$ and then decreases to $-5 \mu \mathrm{V} \mathrm{Oe}^{-1} \mathrm{~cm}^{-1}$ at $10 \mathrm{kOe}$. For $\mathrm{H}_{\mathrm{DC}}$ higher than $\pm 2 \mathrm{kOe}$, the courses of $\alpha_{\mathrm{ME}}$ are identical for both directions of the field sweep. Surprisingly, between -2 and $+2 \mathrm{kOe}$ an inverted hysteresis is formed, that is, upon decreasing the (positive) field strength a ME voltage of zero is found already for a positive coercive field, whereas at $\mathrm{H}_{\mathrm{DC}}=0$ a $\alpha_{\mathrm{ME}}$ with an opposite sign is observed. As described later this behavior is remarkably different from the one of $\mathrm{CoFe}_{2} \mathrm{O}_{4}-\mathrm{BaTiO}_{3}$ composites.

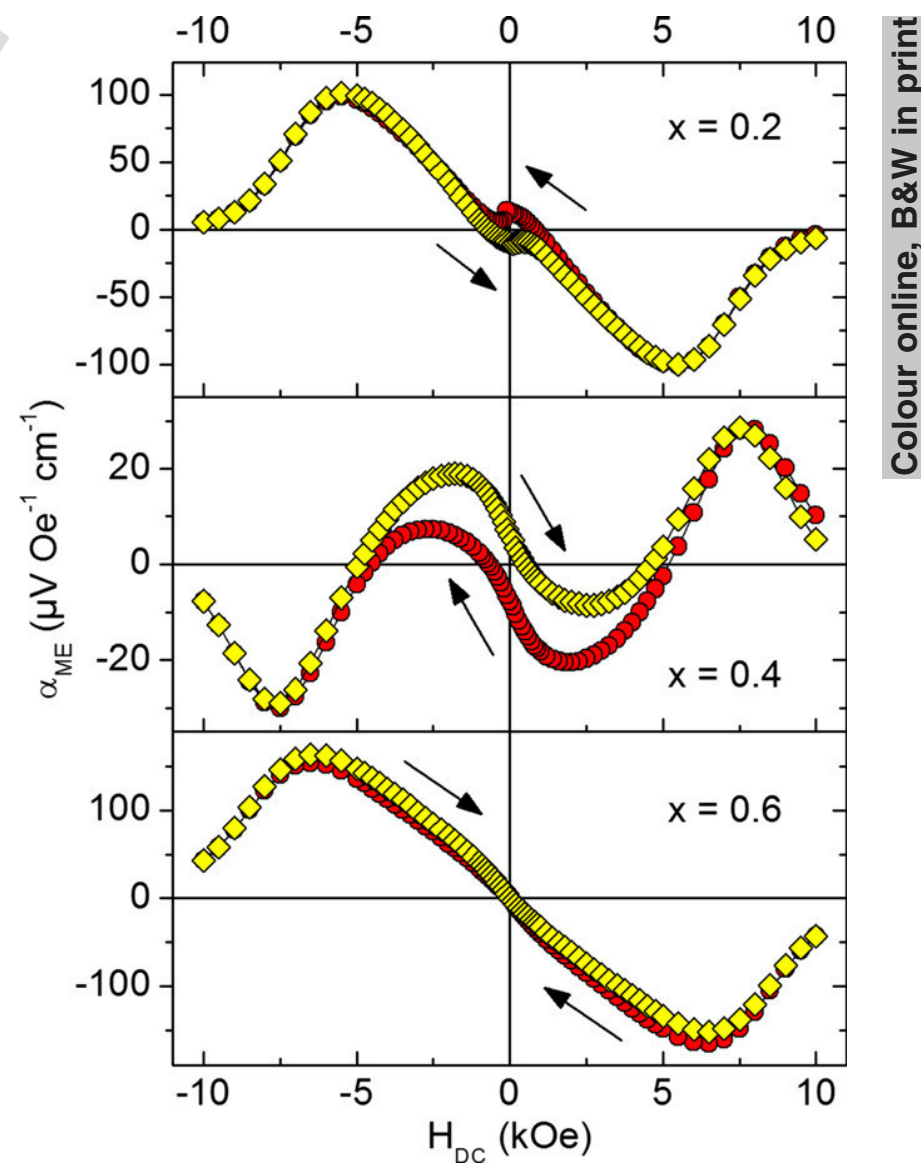

FIGURE 4 Magnetic field-dependent magnetoelectric coefficients $\alpha_{\mathrm{ME}}$ of $\left(\mathrm{Co}_{1 / 3} \mathrm{Fe}_{2 / 3}\right)_{x}$ - $\left(\mathrm{BaTiO}_{3}\right)_{(1-x)}$ composites measured at $\mathrm{f}_{\mathrm{AC}}=900 \mathrm{~Hz}$ [Color figure can be viewed at wileyonlinelibrary.com] 


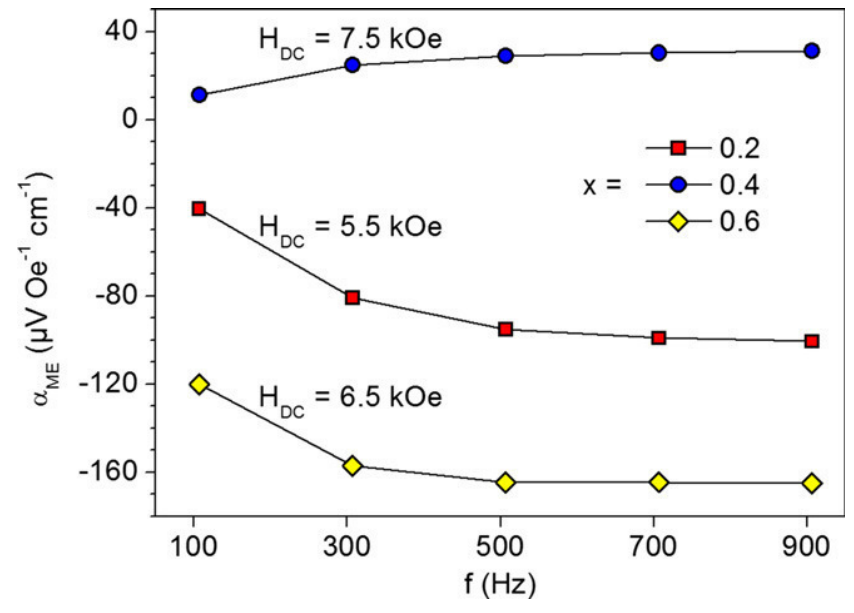

FIGURE 5 Frequency dependence $\mathrm{f}\left(\mathrm{H}_{\mathrm{AC}}\right)$ of the maximal ME coefficients of $\left(\mathrm{Co}_{1 / 3} \mathrm{Fe}_{2 / 3}\right)_{x}-\left(\mathrm{BaTiO}_{3}\right)_{(1-x)}$ composites [Color figure can be viewed at wileyonlinelibrary.com]

Even more astonishing is the magnetoelectric behavior of $0.4 \mathrm{Co}_{1 / 3} \mathrm{Fe}_{2 / 3}-0.6 \mathrm{BaTiO}_{3}$, which turned out to be completely different from the other two samples as shown in Figure 4. Upon increasing the field to $10 \mathrm{kOe}$, the magnetoelectric coefficient first exhibits a minimum at $2.5 \mathrm{kOe}$ with $\alpha_{\mathrm{ME}}=-8.5 \mu \mathrm{V} \mathrm{Oe}^{-1} \mathrm{~cm}^{-1}$, followed by a maximum of $+29 \mu \mathrm{V} \mathrm{Oe}^{-1} \mathrm{~cm}^{-1}$ at $7.5 \mathrm{kOe}$. The $\alpha_{\mathrm{ME}}$ values at $7.5 \mathrm{kOe}$ are independent of the field sweep direction. In contrast, $\alpha_{\mathrm{ME}}$ at $2.5 \mathrm{kOe}$ is significantly larger $\left(-20.5 \mu \mathrm{V} \mathrm{Oe}^{-1} \mathrm{~cm}^{-1}\right)$ when $\mathrm{H}_{\mathrm{DC}}$ is decreased from $10 \mathrm{kOe}$ to zero. As a consequence, a broad hysteresis is formed between roughly +5 and $-5 \mathrm{kOe}$.

In Figure 4, the magnetoelectric behavior for the sample with $x=0.6$ is shown. The course of $\alpha_{\mathrm{ME}}$ is almost similar to the one of $x=0.2$. The maximum of $-165 \mu \mathrm{V} \mathrm{Oe} \mathrm{Cm}^{-1}$ at $6.5 \mathrm{kOe}$ observed for $0.6 \mathrm{Co}_{1 / 3} \mathrm{Fe}_{2 /}$ ${ }_{3}-0.4 \mathrm{BaTiO}_{3}$ is the highest $\alpha_{\mathrm{ME}}$ value of the investigated samples. It is noteworthy that no hysteresis occurs for this composition and that the DC field at which the maximum $\alpha_{\mathrm{ME}}$ is reached is about $1 \mathrm{kOe}$ higher than for $x=0.2$.

We emphasize that the DC field dependence of the magnetoelectric effect is completely different from composites of $\mathrm{BaTiO}_{3}$ in combination with $\mathrm{CoFe}_{2} \mathrm{O}_{4}$ as shown exemplarily in Figure $\mathrm{S} 5$ of the supplementary for the composition $0.5 \mathrm{CoFe}_{2} \mathrm{O}_{4}-0.5 \mathrm{BaTiO}_{3}$ (please note that the sample was obtained from oxidation of a $\mathrm{Co}_{1 / 3} \mathrm{Fe}_{2 / 3}-\mathrm{BaTiO}_{3}$ composite as described $\mathrm{in}^{22}$ ). In particular the sign of $\alpha_{\mathrm{ME}}$ is inverted, although both samples were electrically poled in the same direction. This can be explained taking into account the different magnetostrictions of $\mathrm{Co}_{1 / 3} \mathrm{Fe}_{2 / 3}$ and $\mathrm{CoFe}_{2} \mathrm{O}_{4}$. While $\mathrm{Co}_{1 / 3} \mathrm{Fe}_{2 / 3}$ has a positive magnetostriction, ${ }^{19} \lambda$ of $\mathrm{CoFe}_{2} \mathrm{O}_{4}$ is negative. ${ }^{32}$

From Figure 5 it can be seen that the ME coefficient slightly increases with frequency up to $500 \mathrm{~Hz}$. At higher frequencies only minimal changes were observed. Again, the different behavior of the sample with $x=0.4$ becomes evident. While the other two samples exhibit negative ME voltages at positive fields, positive maximum values were observed for this composition.

\section{4 | CONCLUSIONS}

We report the first magnetoelectric investigations on particulate composites of $\mathrm{BaTiO}_{3}$ in combination with a $\mathrm{Co} / \mathrm{Fe}$ alloy. $\left(\mathrm{Co}_{1 / 3} \mathrm{Fe}_{2 / 3}\right)_{x}-\left(\mathrm{BaTiO}_{3}\right)_{(1-x)}$ samples with $x=0.2,0.4$ and 0.6 were prepared by sintering in a reducing atmosphere. The samples possess a uniform $\mathrm{BaTiO}_{3}$ matrix with embedded $\mathrm{Co}_{1 / 3} \mathrm{Fe}_{2 / 3}$ particles. In contrast to cobalt ferritebarium titanate composites, the dielectric properties are comparable to the ones of pure $\mathrm{BaTiO}_{3}$. Soft ferromagnetic hystereses with large saturation magnetizations of $2.5 \mu_{\mathrm{B}} /$ atom were observed for all three compositions. Magnetoelectric investigations of the $\mathrm{Co}_{1 / 3} \mathrm{Fe}_{2 / 3}-\mathrm{BaTiO}_{3}$ system revealed surprising $\mathrm{H}_{\mathrm{DC}}$. Compared to $\mathrm{CoFe}_{2} \mathrm{O}_{4}-\mathrm{BaTiO}_{3}$ composites, an inversed sign and a completely different course of $\alpha_{\mathrm{ME}}$ was observed. In addition, significant deviations in the magnetoelectric behavior for the three $\mathrm{Co}_{1 /}$ ${ }_{3} \mathrm{Fe}_{2 / 3}-\mathrm{BaTiO}_{3}$ ratios were found. For $x=0.2$ and 0.6 negative maximum values of $\alpha_{\mathrm{ME}}$ occur at positive $\mathrm{H}_{\mathrm{DC}}$ but both the values of $\alpha_{\mathrm{ME}(\max )}$ and of the corresponding magnetic fields are distinctively different. Even more surprising is the ME behavior of the intermediate composition $0.4 \mathrm{Co}_{1 / 3} \mathrm{Fe}_{2 / 3}-0.6 \mathrm{BaTiO}_{3}$. For this sample a broad ME-hysteresis between +5 and $-5 \mathrm{kOe}$ was found and shows an unusual change in sign from a negative maximum at $\mathrm{H}_{\mathrm{DC}} \approx 2.5 \mathrm{kOe}$ to a positive one at $7.5 \mathrm{kOe}$.

In summary this paper describes a new synthesis route to magnetoelectric metal/alloy- $\mathrm{BaTiO}_{3}$ composites with $0-3$ connectivity and the first ME measurements of this system. The unique behavior of the samples opens the door to a completely uninvestigated field of new composites with fascinating magnetoelectric properties.

\section{ACKNOWLEDGMENTS}

Financial support by the German Research Foundation within the Collaborative Research Centre SFB 762, Functionality of Oxide Interfaces, is gratefully acknowledged.

\section{REFERENCES}

1. Schmid H. Multi-ferroic magnetoelectrics. Ferroelectrics. 1994;162:317-338.

2. Spaldin NA, Fiebig M. The renaissance of magnetoelectric multiferroics. Science. 2005;309:391-392.

3. Zhai J, Xing Z, Dong S, Li J, Viehland D. Magnetoelectric laminate composites: an overview. J Am Chem Soc. 2008;91:351358. 
4. Srinivasan G. Magnetoelectric composites. Annu Rev Mater Res. 2010;40:153-178.

5. Shen HQ, Wang YG, Xie D, Cheng JH. Magnetoelectric effect in $\mathrm{FeCo} / \mathrm{PMN}-\mathrm{PT} / \mathrm{FeCo}$ trilayers prepared by electroless deposition of $\mathrm{FeCo}$ on PMN-PT crystals with various orientations. J Alloys Compd. 2014;610:11-14.

6. Xie D, Wang YG, Cheng JH. Zero-biased and resonant magnetoelectric effect in magnetostrictive/piezoelectric multilayered composites. J Mater Sci: Mater Electron. 2015;26:3545-3549.

7. Filippov DA, Laletin VM, Firsova TO. Nonlinear magnetoelectric effect in composite multiferroics. Phys Solid State. 2014;56:980984.

8. Okazaki T, Mikami K, Furuya Y, Kishi Y, Yajima Z, Kubota T. Magnetic properties of thin-film $\mathrm{Fe}-\mathrm{Pd}$ alloy and magnetoelectric coupling in $\mathrm{Fe}-\mathrm{Pd} / \mathrm{Ag} / \mathrm{PZT} / \mathrm{Ag} / \mathrm{Fe}-\mathrm{Pd}$ laminate composites. J Alloys Compd. 2013;577S:S300-S304.

9. Nair SS, Pookat G, Saravanan V, Anantharaman MR. Lead free heterogeneous multilayers with giant magneto electric coupling for microelectronics/microelectromechanical systems applications. J Appl Phys. 2013;114:064309.

10. Park JH, Jang HM, Kim HS, Park CG, Lee SG. Strain-mediated magnetoelectric coupling in $\mathrm{BaTiO}_{3}$-Co nanocomposite thin films. Appl Phys Lett. 2008;92:062908.

11. Gojdka B, Hrkac V, Xiong J, et al. A critical evaluation of the 0 3 approach for magnetoelectric nanocomposites with metallic nanoparticles. J Appl Phys. 2012;112:044303.

12. Hyuga H, Hayashi Y, Sekino T, Niihara K. Fabrication process and electrical properties of $\mathrm{BaTiO}_{3} / \mathrm{Ni}$ nanocomposites. Nanostruct Mater. 1997;9:547-550.

13. Hwang HJ, Toriyama M, Sekino T, Niihara K. In-situ fabrication of ceramic/metal nanocomposites by reduction reaction in barium titanate-metal oxide systems. J Eur Ceram Soc. 1998;18:21932199.

14. Pecharromán C, Esteban-Betegón F, Bartolomé JF, López-Esteban $\mathrm{S}$, Moya JS. New percolative $\mathrm{BaTiO}_{3}-\mathrm{Ni}$ composites with a high and frequency-independent dielectric constant $(\varepsilon \mathrm{r} \approx 80000)$. Adv Mater. 2001;13:1541-1544.

15. Huang Y-C, Chen S-S, Tuan W-H. Process window of BaTiO3$\mathrm{Ni}$ ferroelectric-ferromagnetic composites. $J$ Am Ceram Soc. 2007;90:1438-1443.

16. Yoon S, Pithan C, Waser R, et al. Electronic conduction mechanisms in $\mathrm{BaTiO}_{3}-\mathrm{Ni}$ composites with ultrafine microstructure obtained by spark plasma sintering. $J$ Am Ceram Soc. 2010;93:4075-4080.

17. Yoon S, Dornseiffer J, Schneller T, et al. Percolative $\mathrm{BaTiO}_{3}-\mathrm{Ni}$ composite nanopowders from alkoxide-mediated synthesis. $J$ Eur Ceram Soc. 2010;30:561-567.

18. Sánchez-Jiménez PE, Pérez-Maqueda LA, Diánez MJ, Perejón A, Criado JM. Mechanochemical preparation of $\mathrm{BaTiO}_{3}-\mathrm{Ni}$ nanocomposites with high dielectric constant. Compos Struct. 2010;92:2236-2240.

19. Williams SR. The joule magnetostrictive effect in a group of cobalt-iron alloys. Rev Sci Instrum. 1932;3:675-683.
20. Bardos DI. Mean magnetic moments in bcc Fe-Co alloys. J Appl Phys. 1969;40:1371-1372.

21. Felser C, Fecher GH, Balke B. Spintronik: eine Herausforderung für Materialwissenschaften und Festkörperchemie. Angew Chem. 2007;119:680-713.

22. Walther T, Straube U, Köferstein R, Ebbinghaus SG. Hysteretic magnetoelectric behavior of $\mathrm{CoFe}_{2} \mathrm{O}_{4}-\mathrm{BaTiO}_{3}$ composites prepared by reductive sintering and reoxidation. J Mater Chem C. 2016;4:4792-4799.

23. Marks GW, Monson LA. Effect of certain group IV oxides on dielectric constant and dissipation factor of barium titanate. Ind Eng Chem. 1955;47:1611-1620.

24. Efros AL, Shklovskii BI. Critical behaviour of conductivity and dielectric constant near the metal-non-metal transition threshold. Phys Status Solidi B. 1976;76:475-485.

25. Mitoseriu L, Buscaglia V. Intrinsic/extrinsic interplay contributions to the functional properties of ferroelectric-magnetic composites. Phase Transitions. 2006;79:1095-1121.

26. Gupta A, Chatterjee R. Dielectric and magnetoelectric properties of $\mathrm{BaTiO}_{3}-\mathrm{Co}_{0.6} \mathrm{Zn}_{0.4} \mathrm{Fe}_{1.7} \mathrm{Mn}_{0.3} \mathrm{O}_{4}$ composite. J Eur Ceram Soc. 2013;33:1017-1022.

27. Köferstein R, Ebbinghaus SG. $\mathrm{BaGeO}_{3}$ as sintering additive for $\mathrm{BaTiO}_{3}-\mathrm{MgFe}_{2} \mathrm{O}_{4}$ composite ceramics. RSC Adv. 2015;5:7149171499.

28. Ghosh S, Sanyal B, Chaudhuri CB, Mookerjee A. Electronic structure and magnetism of disordered bcc Fe alloys. Eur Phys $J$ B. 2001;23:455-461.

29. Ohnuma I, Enoki H, Ikeda O, et al. Phase equilibria in the $\mathrm{Fe}-$ Co binary system. Acta Mater. 2002;50:379-393.

30. Kuhrt C, Schultz L. Formation and magnetic properties of nanocrystalline mechanically alloyed Fe-Co and Fe-Ni. J Appl Phys. 1993;73:6588-6590.

31. Yu RH, Basu S, Ren L, et al. High temperature soft magnetic materials: FeCo alloys and composites. IEEE Trans Magn. 2000;36:3388-3393.

32. Nlebedim IC, Snyder JE, Moses AJ, Jiles DC. Dependence of the magnetic and magnetoelastic properties of cobalt ferrite on processing parameters. J Magn Magn Mater. 2010;322:3938-3942.

\section{SUPPORTING INFORMATION}

Additional Supporting Information may be found online in the supporting information tab for this article.

How to cite this article: Walther T, Köferstein R, Ebbinghaus SG. Novel magnetoelectric composites of cobalt iron alloy and barium titanate. J Am Ceram Soc. 2017;00:1-7. doi:10.1111/jace.14744. 


\section{Author Query Form}

\section{Journal: JACE}

\section{Article: 14744}

Dear Author,

During the copy-editing of your paper, the following queries arose. Please respond to these by marking up your proofs with the necessary changes/additions. Please write your answers on the query sheet if there is insufficient space on the page proofs. Please write clearly and follow the conventions shown on the attached corrections sheet. If returning the proof by fax do not write too close to the paper's edge. Please remember that illegible mark-ups may delay publication.

Many thanks for your assistance.

\begin{tabular}{|l|l|l|}
\hline Query reference & Query & Remarks \\
\hline 1 & $\begin{array}{l}\text { AUTHOR: Please confirm that given names (red) and surnames/family names (green) have } \\
\text { been identified correctly. }\end{array}$ & $\begin{array}{l}\text { AUTHOR: Please check that the title, author names, affiliations, and corresponding author } \\
\text { information is listed accurately for publication. }\end{array}$ \\
\hline 2 & &
\end{tabular}




\section{Proof Correction Marks}

Please correct and return your proofs using the proof correction marks below. For a more detailed look at using these marks please reference the most recent edition of The Chicago Manual of Style and visit them on the Web at: http://www.chicagomanualofstyle.org/home. html

\begin{tabular}{|c|c|c|}
\hline Instruction to typesetter & Textual mark & Marginal mark \\
\hline Leave unchanged & ... under matter to remain & (stet) \\
\hline $\begin{array}{l}\text { Insert in text the matter } \\
\text { indicated in the margin }\end{array}$ & $\wedge$ & $\begin{array}{l}\wedge \text { followed by new } \\
\text { matter }\end{array}$ \\
\hline Delete & $\begin{array}{l}\sigma_{\text {through single character, rule or underline }} \\
\text { or }\end{array}$ & e \\
\hline $\begin{array}{l}\text { Substitute character or } \\
\text { substitute part of one or } \\
\text { more word(s) }\end{array}$ & $\begin{array}{l}\sigma \text { through all characters to be deleted } \\
K \text { through letter or } \\
\longrightarrow \text { through characters }\end{array}$ & $\begin{array}{l}\text { new character } \lambda \text { or } \\
\text { new characters } \lambda\end{array}$ \\
\hline Change to italics & — under matter to be changed & ital \\
\hline Change to capitals & $\equiv$ under matter to be changed & CADS \\
\hline Change to small capitals & $=$ under matter to be changed & (50) \\
\hline Change to bold type & $\sim$ under matter to be changed & (bf) \\
\hline Change to bold italic & $\bar{\sim}$ under matter to be changed & (bf+ital \\
\hline Change to lower case & B & (2) \\
\hline Insert superscript & $\checkmark$ & $\begin{array}{l}\checkmark \text { under character } \\
\text { e.g. } \vee\end{array}$ \\
\hline Insert subscript & $\wedge$ & $\begin{array}{l}\wedge \text { over character } \\
\text { e.g. } \hat{\imath}\end{array}$ \\
\hline Insert full stop & $\odot$ & $\odot$ \\
\hline Insert comma & $\hat{\jmath}$ & $\hat{\jmath}$ \\
\hline Insert single quotation marks & 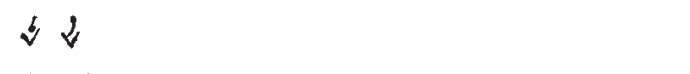 & $b 2$ \\
\hline Insert double quotation marks & $\ddot{v}$ & 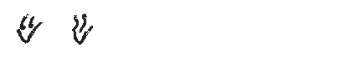 \\
\hline Insert hyphen & $=$ & $=$ \\
\hline Start new paragraph & $\Phi$ & $\phi$ \\
\hline Transpose & $\sqcup$ & $\sqcup$ \\
\hline Close up & linking $\bigcirc$ characters & 2 \\
\hline $\begin{array}{l}\text { Insert or substitute space } \\
\text { between characters or words }\end{array}$ & \# & \# \\
\hline $\begin{array}{l}\text { Reduce space between } \\
\text { characters or words }\end{array}$ & J & こ \\
\hline
\end{tabular}

